\title{
The role of the mesangial cell in proliferative glomerulonephritis
}

\author{
A. M. DAVISON, D. THOMSON, MARY K. MACDONALD, W. S. UTTLEY, \\ AND J. S. ROBSON \\ From the Department of Pathology, University of Edinburgh, the Royal Hospital for Sick Children, \\ Edinburgh, and the Medical Renal Unit, Department of Medicine, Royal Infirmary, Edinburgh
}

SYNOPSIS In 40 patients with a histological diagnosis of proliferative glomerulonephritis the deposition of immunoglobulins, complement $\left(\mathrm{C}_{3}\right)$, and fibrin/fibrinogen has been assessed by immunofluorescence and electron microscopy. The results of such examinationshave been correlated with the outcome of the illness.

In minor or resolving disease there is usually minor functional impairment, a good response to therapy or spontaneous resolution, the deposition of small amounts of material in glomerular capillary walls, and active mesangial removal. In moderate to marked disease there is initially a moderately severe functional disorder, a good response to therapy, considerable deposition of material in glomerular capillary walls but with less active mesangial regions than in the previous group. In progressive glomerulonephritis there was initial severe functional disorder, poor response to therapy, large amounts of material deposited within capillary walls, and active mesangial regions which were greatly enlarged, containing numerous deposits. In the rapidly progressive group there was severe functional disorder with poor response to therapy, the deposition of only small amounts of material within capillary walls, the lack of any significant mesangial cell reaction, and the formation of epithelial crescents.

The results of the study indicate that in proliferative glomerulonephritis following the deposition of material in glomerular capillary loops, the progression of the disease is, to some extent at least, dependent upon the ability of the mesangial cell to remove such material.

The phagocytic capacity of the mesangial cell has been demonstrated for a wide variety of materials (Mellors and Brzosko, 1961; Farquhar and Palade, 1962; Latta and Maunsbach, 1962; Michael, Fish, and Good, 1967). It has been suggested that an important function of the mesangial cell is to remove and catabolize material which has become deposited within the glomerular capillary wall, thus restoring the integrity of this structure (Farquhar and Palade, 1962).

Proliferative glomerulonephritis is associated with the deposition of immunoglobulin, complement, and fibrin within the glomerulus. The natural history and response to treatment of this disease may depend upon the ability of the mesangium to remove and catabolize such deposited material. We have studied the distribution within the glomerulus of such material by electron and immunofluorescence microscopy in 40 patients with proliferative glomeruReceived for publication 1 December 1972. lonephritis and correlated the findings with the outcome of the illness.

Patients

Percutaneous renal biopsy tissue was obtained from 40 patients before the introduction of any specific therapy. Proliferative glomerulonephritis was diagnosed on the following histological criteria: (1) an increase in the number of glomerular cells, mesangial or endothelial, or of the epithelial cells of Bowman's capsule; (2) diffuse involvement of all glomeruli.

Details of initial renal function, response to treatment, and outcome of the illness are given in table I.

\section{Methods}

IMMUNOFLUORESCENCE

Tissue obtained at percutaneous renal biopsy was 


\begin{tabular}{|c|c|c|c|c|c|c|c|c|c|c|c|}
\hline \multirow[t]{2}{*}{ No. } & \multirow[t]{2}{*}{$\operatorname{Sex}$} & \multirow[t]{2}{*}{ Age } & \multicolumn{3}{|c|}{ Initial Renal Function } & \multirow[t]{2}{*}{ Treatment } & \multirow[t]{2}{*}{ Response } & \multicolumn{3}{|c|}{ Follow-up of Renal Function } & \multirow{2}{*}{$\begin{array}{l}\text { Duration } \\
\text { (months) }\end{array}$} \\
\hline & & & $C C r$ & $P$ & $\boldsymbol{H}$ & & & $C \mathrm{Cr}$ & $P$ & $H$ & \\
\hline
\end{tabular}

\begin{tabular}{|c|c|c|c|c|c|c|c|c|c|c|c|}
\hline \multicolumn{12}{|c|}{ Minor or Resolving Proliferative Glomerulonephritis } \\
\hline 1 & $\mathbf{F}$ & 5 & $\mathbf{N}$ & + & + & Antibiotic & Good & $\mathbf{N}$ & - & - & 20 \\
\hline 2 & $\mathbf{F}$ & 18 & $\mathbf{N}$ & + & + & Indomethacin & Nil & $\mathbf{N}$ & + & - & 19 \\
\hline 3 & $\mathbf{M}$ & 14 & $\mathbf{N}$ & + & + & Antibiotic & Good & $\mathbf{N}$ & - & - & 18 \\
\hline 4 & $\mathbf{M}$ & 24 & $\mathbf{N}$ & - & + & Nil & - & $\mathbf{N}$ & - & - & 15 \\
\hline 5 & $\mathbf{F}$ & 25 & $\mathbf{N}$ & + & - & Prednisone & Good & $\mathbf{N}$ & - & - & 15 \\
\hline 6 & $\mathbf{F}$ & 55 & $\mathbf{N}$ & + & - & Nil & - & $\mathbf{N}$ & + & - & 15 \\
\hline 7 & $\mathbf{M}$ & 8 & $\downarrow$ & + & - & Antibiotic & Good & $\mathbf{N}$ & - & - & 15 \\
\hline 8 & $\mathbf{M}$ & 12 & $\mathbf{N}$ & - & + & Nil & - & $\mathbf{N}$ & - & - & 12 \\
\hline 9 & $\mathbf{M}$ & 7 & $\mathbf{N}$ & + & + & Nil & 一 & $\mathbf{N}$ & - & + & 14 \\
\hline 10 & $\mathbf{M}$ & 9 & $\mathbf{N}$ & + & - & Prednisone & Good & $\mathbf{N}$ & - & - & 12 \\
\hline \multirow[t]{2}{*}{11} & $\mathbf{M}$ & 11 & $\mathbf{N}$ & + & - & Prednisone & & & & & \\
\hline & & & & & & Cyclophosphamide & Good & $\mathbf{N}$ & - & - & 12 \\
\hline 12 & $\mathbf{F}$ & 4 & $\mathbf{N}$ & + & - & Prednisone & Good & $\mathbf{N}$ & - & - & 12 \\
\hline 13 & $\mathbf{F}$ & 3 & $\mathbf{N}$ & + & + & Nil & - & $\mathbf{N}$ & - & - & 12 \\
\hline 14 & $\mathbf{M}$ & 29 & $\mathbf{N}$ & + & - & Nil & 一 & $\mathbf{N}$ & - & - & 7 \\
\hline \multicolumn{12}{|c|}{ Moderate Proliferative Glomerulonephrit is } \\
\hline 15 & $\mathbf{M}$ & 3 & $\mathbf{N}$ & + & - & Cyclophosphamide & Good & $\mathbf{N}$ & - & - & 20 \\
\hline \multirow[t]{2}{*}{16} & $\mathbf{M}$ & 7 & $\mathbf{N}$ & + & - & Prednisone & & & & & \\
\hline & & & & & & Cyclophosphamide & Good & $\mathbf{N}$ & - & - & 19 \\
\hline 17 & $\mathbf{F}$ & 17 & $\mathbf{N}$ & + & + & Antibiotic & Good & $\mathbf{N}$ & + & - & 18 \\
\hline 18 & $\mathbf{M}$ & 12 & $\downarrow$ & + & - & Prednisone & & $N$ & & & \\
\hline 19 & $\mathbf{F}$ & 44 & $\downarrow$ & + & - & $\begin{array}{l}\text { Cyclophosphamide } \\
\text { Prednisone }\end{array}$ & $\begin{array}{l}\text { Good } \\
\text { Good }\end{array}$ & $\mathbf{N}$ & - & - & $\begin{array}{l}13 \\
12\end{array}$ \\
\hline 20 & $\mathbf{F}$ & 65 & $\downarrow$ & + & + & Prednisone & Poor & $\downarrow$ & - & + & 9 \\
\hline 21 & $\mathbf{F}$ & 32 & $\mathbf{N}$ & + & - & Hypotensive & Poor & $Y$ & + & - & 9 \\
\hline 22 & $\mathbf{F}$ & 48 & 1 & + & - & Prednisone & Good & $\downarrow$ & - & - & 9 \\
\hline 23 & $\mathbf{M}$ & 3 & $\mathbf{N}$ & + & - & Prednisone & Good & $\mathbf{N}$ & - & - & 7 \\
\hline 24 & $\mathbf{F}$ & 9 & $\mathbf{N}$ & + & - & Nil & Nil & $\mathbf{N}$ & + & - & 7 \\
\hline 25 & $\mathbf{M}$ & 26 & $\mathbf{N}$ & + & + & Indomethacin & Good & $\mathbf{N}$ & - & - & 10 \\
\hline 26 & $\mathbf{M}$ & 5 & $\mathbf{N}$ & - & + & Antibiotic & Good & $\mathbf{N}$ & - & - & 19 \\
\hline 27 & $\mathbf{F}$ & 54 & $\downarrow$ & + & + & Hypotensive & Nil & Died & & & \\
\hline 28 & $\mathbf{F}$ & 21 & $\mathbf{N}$ & + & - & Indomethacin & Good & $\mathbf{N}$ & - & - & 7 \\
\hline \multicolumn{12}{|c|}{ Progressive Glomerulonephritis } \\
\hline 29 & $\mathbf{M}$ & 23 & $\downarrow$ & + & - & Prednisone & Poor & $\mathbf{N}$ & + & - & 19 \\
\hline 30 & $\mathbf{M}$ & 25 & $\downarrow$ & + & + & Indomethacin & Good & $\mathbf{N}$ & - & - & 17 \\
\hline 31 & $\mathbf{M}$ & 20 & $\downarrow$ & + & + & Hypotensive & Poor & $\downarrow$ & + & - & 15 \\
\hline 32 & $\mathbf{M}$ & 60 & $\downarrow$ & + & + & Prednisone & Poor & & + & + & 9 \\
\hline 33 & $\mathbf{M}$ & 69 & $\downarrow$ & + & + & Indomethacin & Poor & Died & & & 3 \\
\hline \multicolumn{12}{|c|}{ Rapidly Progressive Glomerulonephritis } \\
\hline 34 & $\mathbf{M}$ & 64 & \multirow{2}{*}{\multicolumn{3}{|c|}{$\begin{array}{l}\text { Acute renal failure } \\
\text { Acute renal failure }\end{array}$}} & Prednisone & Poor & Dialysis & & & 1 \\
\hline 35 & $\mathbf{M}$ & 24 & & & & Prednisone & Poor & Dialysis & & & 1 \\
\hline 36 & $\mathbf{F}$ & 13 & \multirow{2}{*}{\multicolumn{3}{|c|}{$\stackrel{\downarrow}{\text { Acute renal failure }}$}} & Nil & Nil & $\downarrow$ & \multicolumn{2}{|l|}{+} & 12 \\
\hline 37 & $\mathbf{F}$ & 62 & & & & Prednisone & Poor & Died & \multirow{2}{*}{\multicolumn{2}{|c|}{+}} & 1 \\
\hline 38 & $\mathbf{F}$ & 71 & $\downarrow$ & + & + & Prednisone & Poor & & & & 10 \\
\hline 39 & $\mathbf{F}$ & 17 & 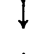 & + & + & $\begin{array}{l}\text { Prednisone } \\
\text { Indomethacin }\end{array}$ & Poor & Dialysis & & & 1 \\
\hline 40 & $\mathbf{M}$ & 20 & $\downarrow$ & + & & Indomethacin & Poor & $\downarrow$ & + & & 8 \\
\hline
\end{tabular}

Table I Clinical details

$C \mathrm{Cr}$, Creatinine clearance; $\boldsymbol{P}$, proteinuria ; $\boldsymbol{H}$, haematuria; $N$, normal; + , present; - , absent; $\downarrow$, reduced.

rapidly frozen, sectioned at $2 \mu$, and fixed in $95 \%$ alcohol for 10 minutes. Duplicate sections were incubated with commercially obtained FITC (Hoechst) antiserum to $I_{g} G, I_{g} A, I_{g} M$, 'complement $\left(\mathrm{C}_{3}\right)$, and fibrin/fibrinogen for $30 \mathrm{~min}$ in a dark, moist chamber at room temperature. Sections were viewed in a Leitz Ortholux microscope, employing an HBO 200 lamp with BG12 and BG38 primary filters and a K510 barrier filter. Photographs were obtained with Ektachrome daylight film (Kodak).

The distribution of immunoglobulins, complement, and fibrin within the glomeruli was observed and recorded without knowledge of the clinical or light microscopy findings. A distinction was made between material in capillary walls (fig 1) and in mesangial areas (fig 2).

\section{ELECTRON MICROSCOPY}

The renal tissue was divided into small blocks of 1 or $2 \mathrm{cmm}$, fixed in $1 \%$ osmium tetroxide or in glutaraldehyde with subsequent osmium fixation, and dehydrated in graded alcohols. The blocks were 
embedded in araldite and thin sections cut on a Porter-Blum MT2 or on an LKB ultratome 1. Sections were stained by lead citrate and uranyl acetate, and viewed in an AEI EM.6.

\section{Results}

MINOR OR RESOLVING PROLIFERATIVE GLOMERULONEPHRITIS

A histological diagnosis of minor or resolving proliferative glomerulonephritis was made in 14 patients; in these cases, slight mesangial cell proliferation and mesangial region enlargement was the only abnormality. Relatively little material was associated within the glomerular capillary wall as detected by either electron or immunofluorescence microscopy. However, a small amount of $I_{g} G$ and fibrin was found in this situation in eight patients by immunofluorescence (fig 1). In addition, immunofluorescence was detected to immunoglobulins,

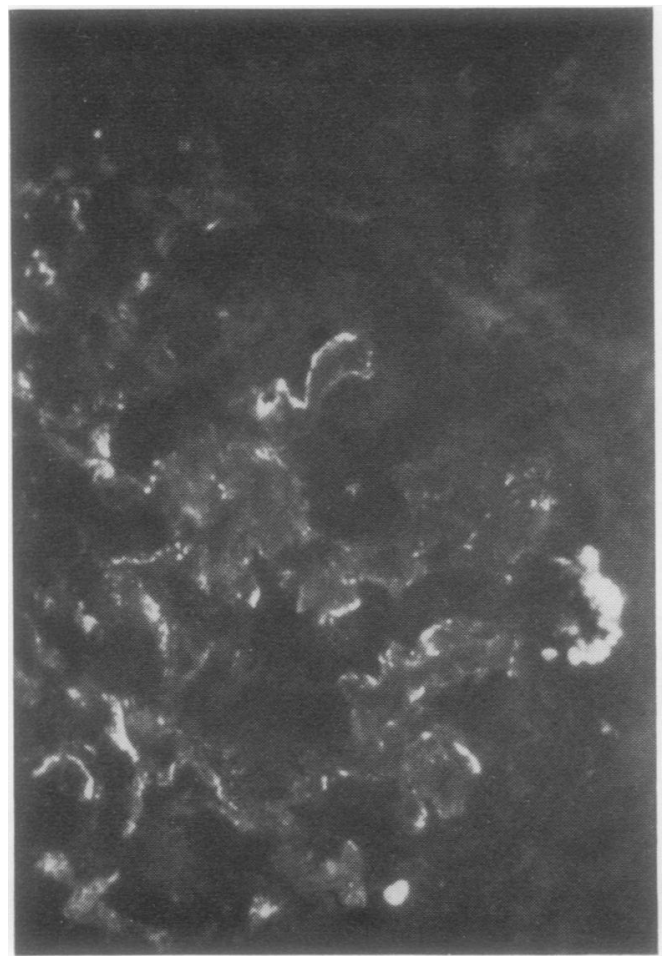

Fig. 1 complement, and fibrin in the mesangial regions of eight patients (fig 2). Overall, in this group there appeared to be relatively more material in the mesangial regions than in the capillary walls (table II).

The electron microscopic appearances of these cases were examined with special reference to the relative amounts of visible deposit in mesangial regions and in the peripheral parts of the walls. Such a comparison is, of course, entirely subjective. Dark granular deposits were numerous in most mesangial regions which were a little enlarged, whereas the only deposits in capillary walls were small, subendothelial foci, and occasional rarefied zones in the same situation, containing a few granules and fibrils suggestive of fibrin deposition. The mesangial cells themselves showed evidence of great activity and $\infty$ tongues of mesangial cytoplasm were frequently 음 seen insinuating themselves between capillary endo- thelium and basement membrane, presumably $\bar{z}$ engaged in removing the subendothelial deposited

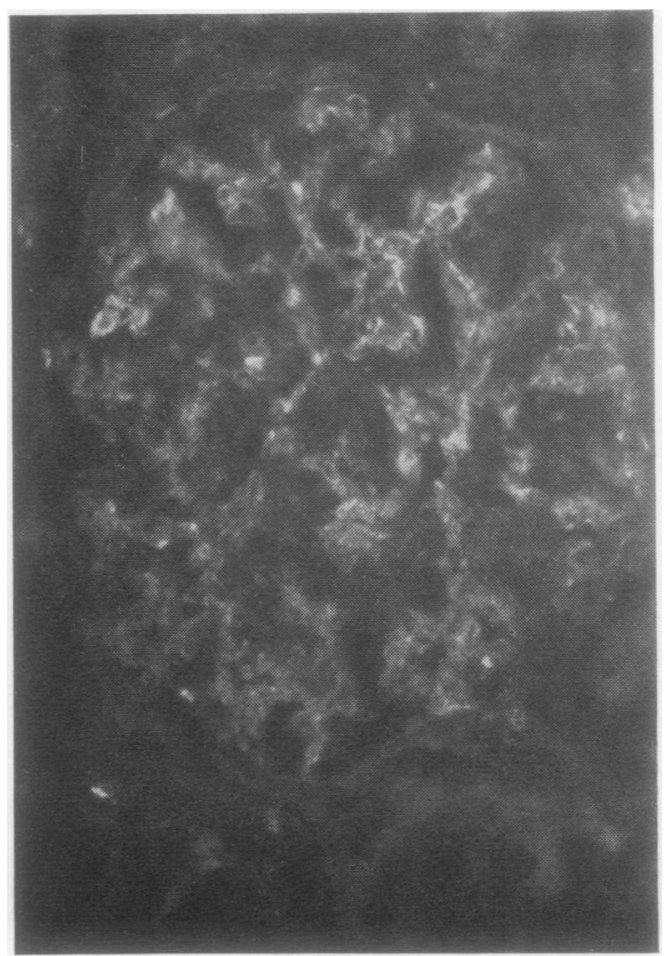

Fig. 2

Fig. 1 Immunofluorescence to $I_{\mathrm{g}} G$ in a glomerulus of a patient with minor or resolving proliferative glomerulonephritis. The material is confined to capillary walls. $\times 400$

Fig. 2 Immunofluorescence to complement $\left(C_{3}\right)$ within the capillary walls and mesangial regions of a patient with minor or resolving proliferative glomerulonephritis. Although material is present within the capillary walls most appears to be concentrated within the mesangial regions. $\times 250$ 


\begin{tabular}{|c|c|c|c|c|c|c|c|c|c|c|}
\hline \multirow[t]{2}{*}{ Patient } & \multicolumn{5}{|c|}{ Capillary Wall } & \multicolumn{5}{|c|}{ Mesangium } \\
\hline & $G$ & $A$ & $M$ & $C_{3}^{\prime}$ & $F$ & $G$ & $A$ & $M$ & $C_{3}^{\prime}$ & $I$ \\
\hline 1 & - & - & - & - & + & + & - & + & + & \\
\hline 2 & $\perp$ & - & - & - & + & \pm & + & + & + & \\
\hline 3 & - & - & - & - & - & \pm & + & - & - & \\
\hline 4 & - & - & - & - & - & - & - & - & - & \\
\hline 5 & - & - & - & - & - & - & - & - & - & \\
\hline 6 & - & - & - & - & - & - & - & - & - & \\
\hline 7 & - & \pm & - & - & - & - & - & + & - & \\
\hline 8 & + & - & - & - & - & - & - & - & - & \\
\hline 9 & - & - & - & - & \pm & + & + & - & - & \\
\hline 10 & + & - & - & + & $=$ & + & - & - & - & \\
\hline 11 & - & - & - & - & - & - & - & - & - & \\
\hline 12 & - & - & - & - & \pm & - & - & - & - & \\
\hline 13 & - & - & - & - & - & - & - & - & - & \\
\hline 14 & - & - & + & + & - & - & - & - & - & \\
\hline
\end{tabular}

Table II Immunofluorescence findings in minor or resolving proliferative glomerulonephritis

$G, 1_{\mathrm{g}} \mathrm{G}, A, 1_{\mathrm{g}} \mathrm{A} ; M, 1_{\mathrm{g}} \mathrm{M} ; C^{\prime}{ }_{3}$ complement $\mathrm{C}_{3}^{\prime} ; F$, fibrin/fibrinogen; + , present; - , absent; \pm , very weak.

material (figs 3 and 4). Similar ultrastructural features were present in three cases $(4,5$, and 6$)$ in which there was no immunofluorescence evidence of capillary wall or mesangial deposition of material.

In this group, 12 of the 14 patients at the time of biopsy had proteinuria seven had haematuria, and only one had depression of renal function as determined by creatinine clearance. Four patients were treated with prednisone, two with antibiotics, and one with indomethacin. At follow-up examination seven to 20 months later, only two still had proteinuria, one had haematuria, and all had normal renal function (table I). This would indicate that these patients had mild functional impairment which had resolved satisfactorily with treatment in eight and spontaneously in four.

\section{MODERATE TO MARKED PROLIFERATIVE GLOMER ULONEPHRITIS}

In 14 patients a diagnosis of moderate to marked proliferative glomerulonephritis was made on the basis of mesangial and endothelial cell proliferation, sometimes with polymorph infiltration. Immunoglobulins, complement, and/or fibrin fibrinogen were present in the capillary walls of 12 and in the mesangial regions of five patients (fig 5). In this group there appeared to be a relative preponderance of material within the capillary walls (table III).

Ultrastructurally these cases showed a wide variation in the amount of abnormal material present in peripheral parts of capillary walls. Some of these walls seemed quite clear of deposit, but in most cases large quantities of granular deposit were seen between basement membrane and endothelium. The amount of deposited material was focally much more

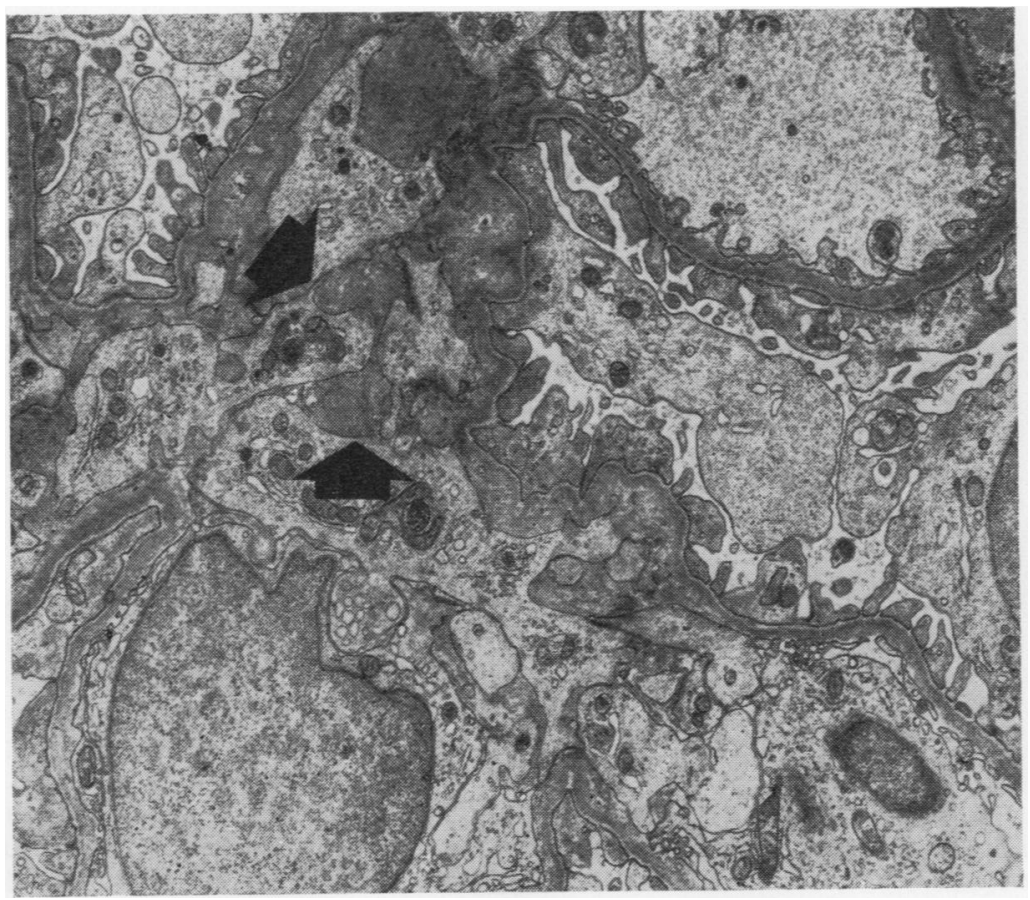

Fig. 3 Electron micrograph of a patient with resolving proliferative glomerulonephritis showing an enlarged mesangial region containing dark deposits (arrows). Capillary walls in this glomerulus are almost free from deposited material (case 1). $\times 7000$ 


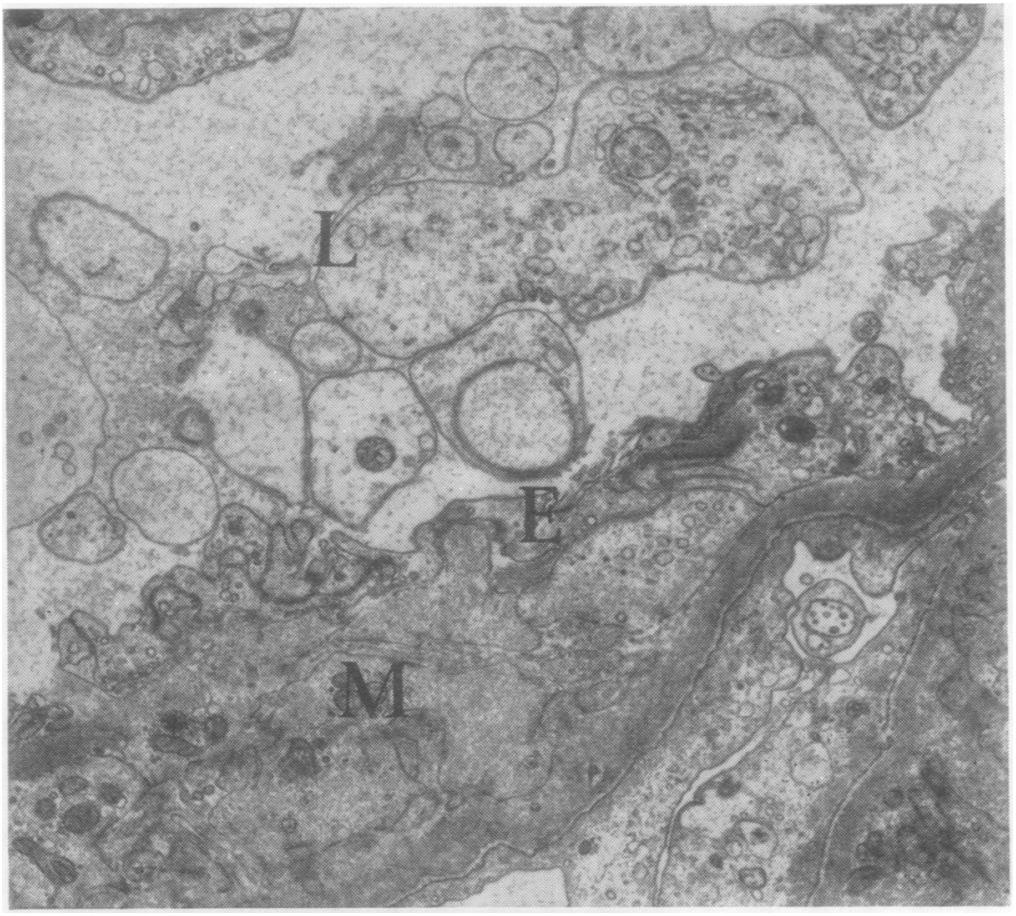

Fig. 4 Tongue of mesangial cytoplasm (M) insinuating between the basement membrane and endothelial cytoplasm (E). There is evidence of subendothelial deposition of electron-dense material. The patient had resolving proliferative glomerulonephritis. Capillary lumen $(\mathrm{L}) . \times 7000$

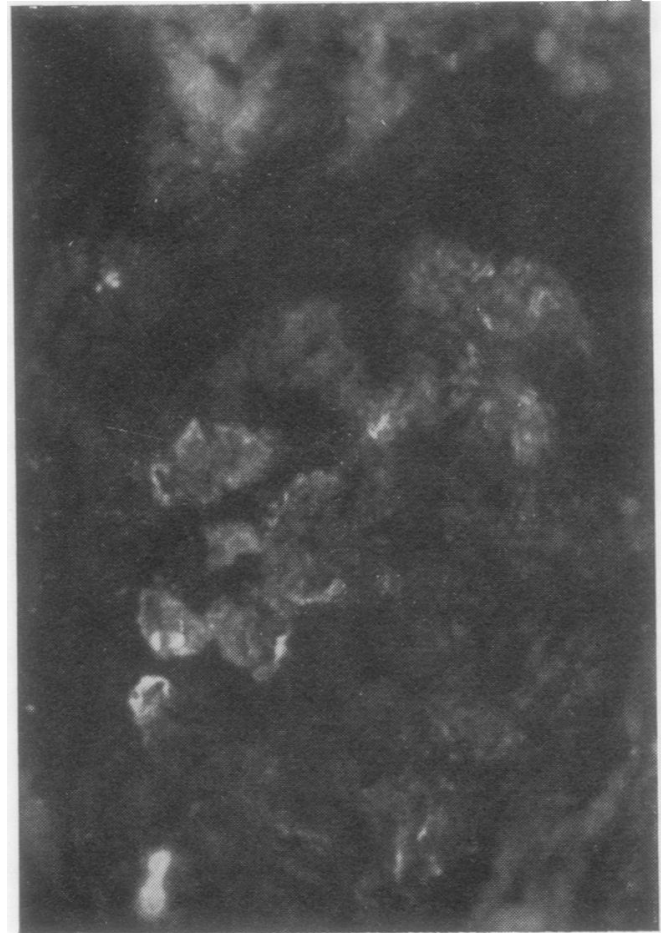

\begin{tabular}{|c|c|c|c|c|c|c|c|c|c|}
\hline \multirow[t]{2}{*}{ Patient } & \multicolumn{5}{|c|}{ Capillary Wall } & \multicolumn{4}{|c|}{ Mesangium } \\
\hline & $G$ & $A$ & $M$ & $C_{3}^{\prime}$ & $F$ & $G$ & $A$ & $M$ & $C^{\prime}{ }_{3}$ \\
\hline
\end{tabular}

Fig. 5 Immunofluorescence to $I_{\mathrm{g}} M$ within the glomerular capillary walls of a patient with moderate proliferative glomerulonephritis (case 28). $\times 400$

Table III Immunofuorescence findings in moderate proliferative glomerulonephritis

$G, I_{g} G ; A, I_{g} A ; M, I_{g} M ; C_{3}$, complement $C_{3} ; F$, fibrin/fibrinogen; + , present; - , absent; \pm , very weak; /, not examined.

than that seen in any capillaries in cases of the $\frac{0}{\Phi}$ previous group. Mesangial regions were again $\stackrel{\rho}{\sim}$ generally enlarged and contained deposited material 0 (fig 6), but in many cases this appearance waso much less marked than in the previous group. $\stackrel{\mathbb{Q}}{\stackrel{Q}{\circ}}$ However, there were some very large regions full of dark, granular material. The mesangial cytoplasm $\frac{\varrho}{\sigma}$ was, on the whole, not particularly active in appearance; mopping up of subendothelial deposit couldo 


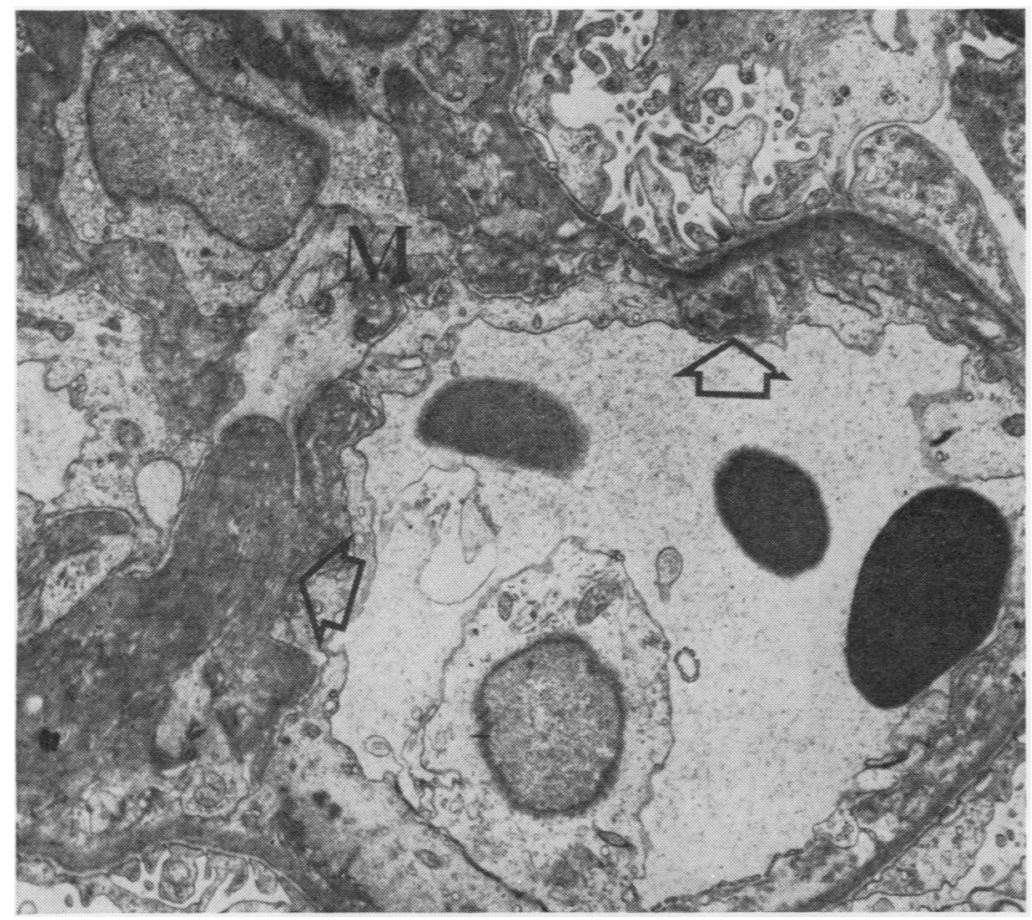

Fig. 6 Reactive mesangial region (M) from a patient with moderate proliferative glomerulonephritis. There is mesangial accumulation of fibrillar and granular electron-dense material which is seen also in a subendothelial position (arrows) (case 27). $\times 4400$

be seen, but this process was not so evident as in the previous group.

Of the 14 patients in this group, five had reduction in renal function, 13 had proteinuria, and five had haematuria when first examined (table I). 'Four patients were treated with prednisone, two with combined prednisone and cyclophosphamide, two with antibiotics, two with only hypotensive agents, two with indomethacin, and one with cyclophosphamide alone; one was given no therapy. Of the five patients with depressed renal function, two showed no improvement over nine months (20 and 22 ), one died from a myocardial infarction, and in two patients renal function returned to normal. One patient, initially normal, developed a significant reduction in renal function over nine months. Of the remainder, two still have proteinuria and one continues to have haematuria.

This group of patients seem to have had a moderately severe functional disorder at the onset of the illness, but most recovered satisfactorily.

\section{PROGRESSIVE PROLIFERATIVE GLOMERULO-} NEPHRITIS

Five patients had histologically progressive proliferative glomerulonephritis with irregular increase in mesangial size and varying degrees of glomerular hyalinization. The most obvious feature on immunofluorescence microscopy was the large amount of material consisting mainly of $\mathrm{IgG}_{\mathrm{g}} \mathrm{C}_{3}$, and fibrin/ fibrinogen within both the capillary walls and the mesangial regions of all glomeruli (fig 7 and table IV). In all patients there was complement $\left(\mathrm{C}_{3}\right)$ and fibrin deposited within capillary walls.

On electron microscopic investigation the most impressive feature was the size of mesangial regions and their protrusion into capillary lumina. This was a generalized lesion and the regions contained numerous scattered deposits which were often not quite so dark as those seen in the mesangium of previous groups. In addition, endothelium was much more swollen than in those other groups, so that capillary lumina were often much reduced on two counts. Mesangial cells were very active in appearance and there was much evidence of phagocytic activity by these cells (fig 8 ).

The peripheral walls of some of the capillaries showed little or no subendothelial deposit, but in others the deposits were numerous though small. In one case the basement membrane appeared darker than normal.

Clinically these patients all had diminution of 


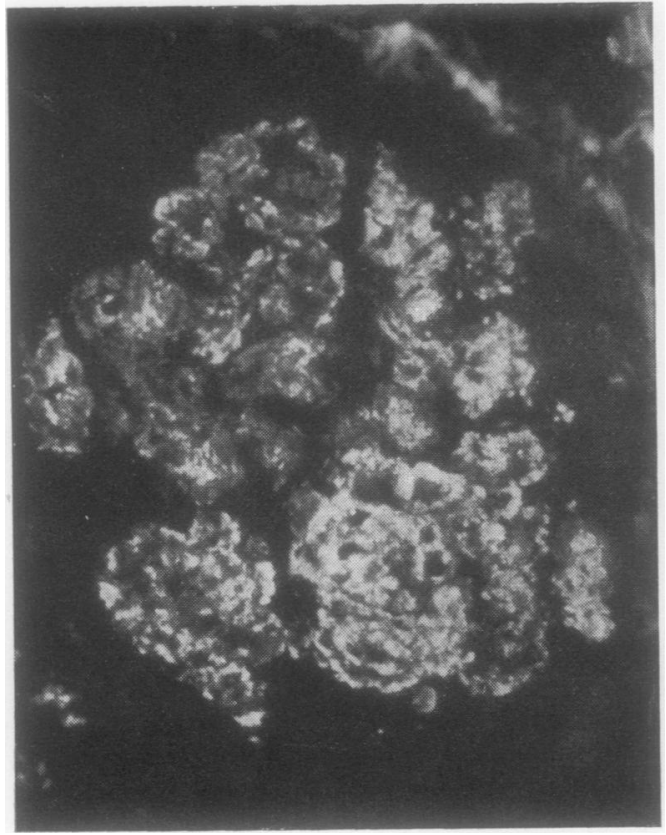

Fig. 7 Immunofluorescence to complement $\left(C_{3}\right)$ in a patient with progressive proliferative glomerulonephritis. Large deposits are visible within glomerular capillary walls and mesangial regions (case 33). $\times 250$

Fig. 8 Enlarged mesangial region (M) containing large dark, dense deposits (arrows) in a patient with progressive proliferative glomerulonephritis. The mesangial region appears to be protruding into the capillary lumen (L) (case 31). $\times 2600$

Fig. 7

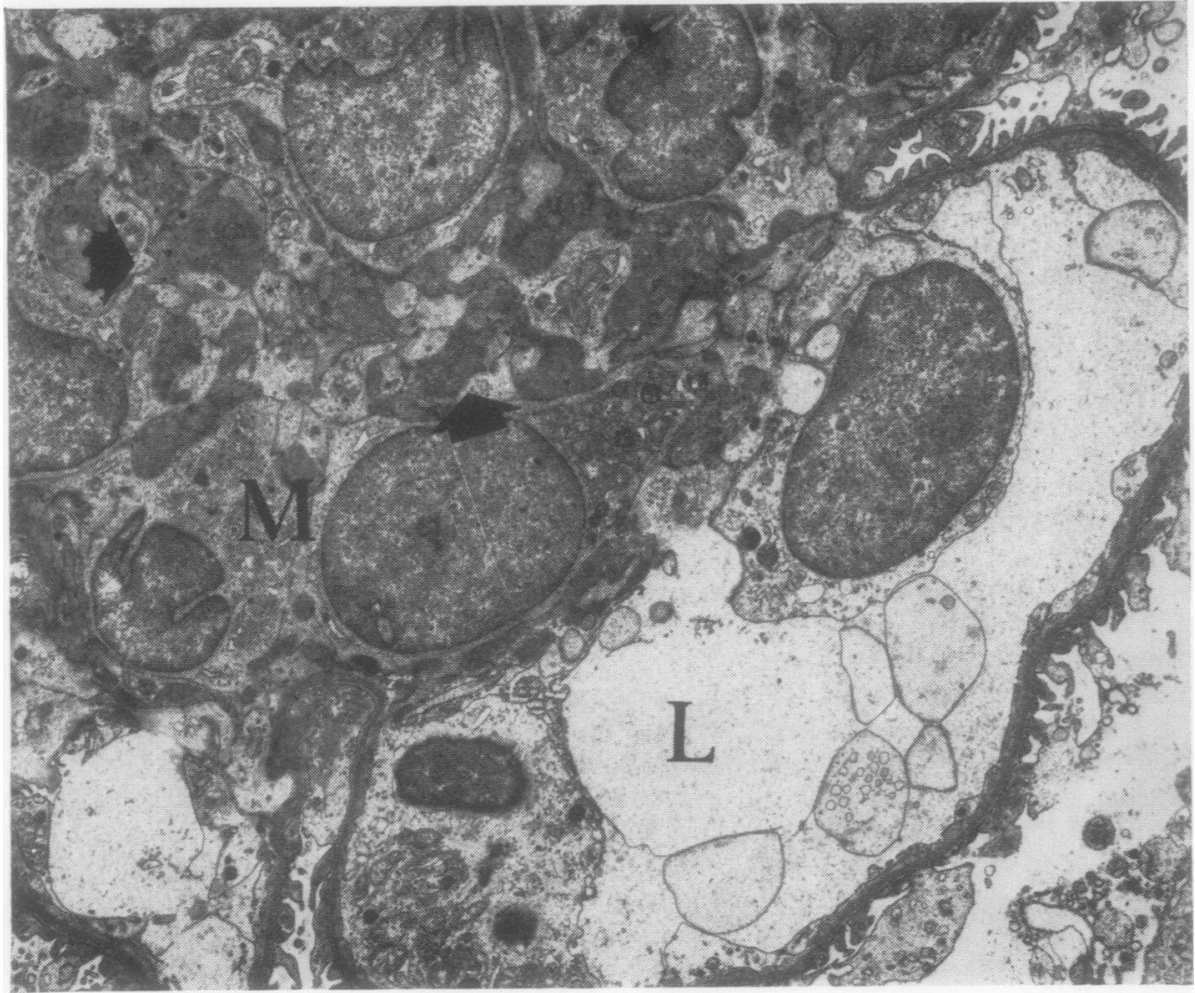

Fig. 8 
renal function, proteinuria, and haematuria at the onset of the illness (table I). Only one patient (30) recovered normal renal function with no proteinuria or haematuria. One patient (29) recovered normal function but continued to have proteinuria. Two patients (31 and 32) still have deteriorating renal function and one patient (33) died from renal failure.

This group of patients showed severe functional impairment at onset and most showed a steady deterioration in spite of therapy.

RAPIDLY PROGRESSIVE GLOMERULONEPHRITIS In six patients there was a severe necrotizing or rapidly progressive glomerulonephritis, the main histological feature being the presence of large crescents surrounding and compressing glomeruli. Typically these glomeruli showed no evidence of intrinsic cellular proliferation, although in some the compressed tuft exhibited either necrosis or considerable infiltration of the capillary walls by fibrin or by other high molecular weight proteins. In immunofluorescence microscopy studies in these biopsies, fibrin fibrinogen was present within crescents (fig 9); there was virtually no material within mesangial regions but some $I_{g} G$, complement and fibrin fibrinogen was demonstrated in the capillary walls of the compressed tufts (table IV).

Electron microscopic examination in these cases was especially interesting. The glomerular mesangial regions were seen to contain very few cells; many were represented by cytoplasm containing varying numbers of organelles, with no visible nuclei (fig 10). A few small scattered deposits of dark granular material were demonstrable in some mesangial regions but these were by no means prominent or numerous. In spite of the deposited material in the subendothelial regions of capillary walls, in only one of the sections viewed was mesangial activity directed towards phagocytosis of these deposits. The capillary basement membrane was generally much darker than normal; subendothelial deposits or

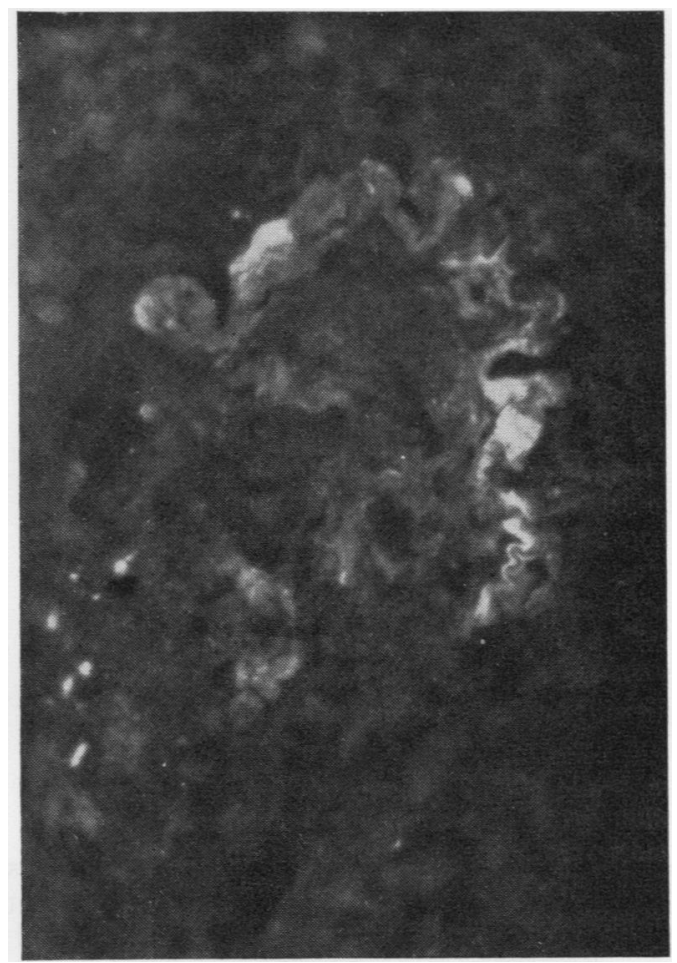

Fig. 9 Immunofluorescence for fibrin within the crescent of a patient with rapidly progressive proliferative glomerulonephritis. There is little material in the compressed glomerular tuft (case 35). $\times 100$

\begin{tabular}{|c|c|c|c|c|c|c|c|c|c|c|c|}
\hline \multirow[t]{2}{*}{ Patient } & \multicolumn{5}{|c|}{ Capillary Wall } & \multicolumn{5}{|c|}{ Mesangium } & \multirow{2}{*}{$\frac{\text { Crescent }}{F}$} \\
\hline & $G$ & $A$ & $M$ & $C_{3}$ & $F$ & $G$ & $A$ & $M$ & $C_{8}$ & $F$ & \\
\hline \multicolumn{12}{|c|}{ Progressive Glomerulonephritis } \\
\hline 29 & + & - & + & + & + & + & + & + & + & - & \\
\hline 30 & + & + & + & 1 & \pm & \pm & \pm & + & 1 & \pm & \\
\hline 31 & - & - & - & + & $\bar{t}$ & $\overline{+}$ & $\vec{t}$ & + & + & $\div$ & \\
\hline 32 & + & + & - & + & + & - & + & + & + & - & \\
\hline 33 & + & + & \pm & + & + & + & + & + & $=$ & $=$ & \\
\hline \multicolumn{12}{|c|}{ Rapidly Progressive Glomerulonephritis } \\
\hline 34 & + & - & - & - & - & - & - & - & - & - & - \\
\hline 35 & + & - & - & + & + & - & - & - & - & - & + \\
\hline 36 & + & - & - & + & + & - & - & + & $\doteq$ & - & - \\
\hline 37 & + & - & + & \pm & \pm & - & - & - & $\bar{z}$ & - & + \\
\hline 38 & - & - & - & 二 & - & - & - & - & - & - & - \\
\hline 39 & - & - & - & - & - & - & - & - & - & - & - \\
\hline 40 & - & + & + & + & \pm & - & - & - & - & - & + \\
\hline
\end{tabular}

Table IV Immunofluorescence findings in progressive and rapidly progressive glomerulonephritis

$G, I_{8} G ; A, I_{8} A ; M, I_{8} M ; C_{3}$, complement $C_{3} ; F$, fibrin/fibrinogen; +, present; - , absent; \pm , very weak; /, not examined. 


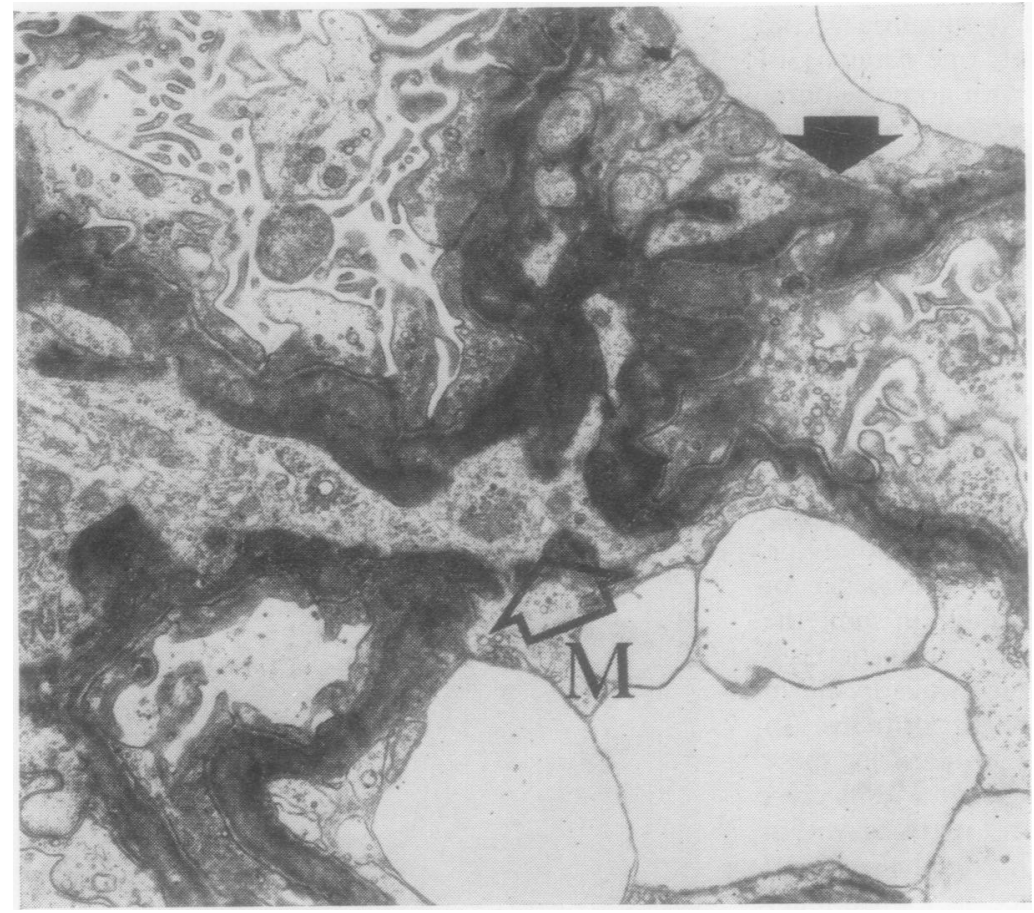

Fig. 10 The mesangial region (M) of a patient with rapidly progressive glomerulonephritis. The basement membrane is unusually dark and there is subendothelial deposition of a dark granular material with some endothelial reaction (dark arrow). The mesangial regions contain no visible nuclei, few deposits, and scattered organelles (case 37). $\times 14000$

deposits in the membrane were moderately numerous but focally distributed. In some places a distinct layer of a rarefied granular or amorphous material, often suggestive of fibrin deposition, was present on the subendothelial aspect.

Three patients in this group had acute renal failure, while the others had severe depression of renal function, proteinuria, and haematuria (table I) at the time of biopsy. Four were treated with prednisone, one with combined prednisone and indomethacin, and one with indomethacin alone. All showed a steady and usually rapid deterioration in renal function, with three requiring long-term intermittent haemodialysis, three suffering further deterioration in renal function, and one dying from acute renal failure.

Thus this group had a very severe disease at onset, with rapid deterioration resulting in death or requiring long-term haemodialysis.

\section{Discussion}

This study shows that many patients who have a minor or resolving proliferative glomerulonephritis on light microscopy have in their capillary walls abnormal material which is removed by mesangial cells so that the walls are almost entirely cleared. The mesangium does not appear to retain the material, at least in its original state. These patients usually have a mild illness with slight functional impairment of short duration. In moderately severe disease most $\overline{0}$ of the abnormal deposits are within the capillary walls, though also present in mesangial regions, suggesting that the mesangium is not coping as adequately with the deposits as in the previous group. 의 These patients have a more severe functional im- $D$ pairment than the previous group and tend to have a을. longer illness; however, most respond satisfactorily to therapy with steroids or anti-inflammatory drugs. In progressive proliferative glomerulonephritis there $\stackrel{N}{\circ}$ is widespread deposition of immunological material $\underset{\omega}{N}$ within the capillary walls and mesangial regions, $\mathcal{O}$ suggesting active removal by mesangial cells, but ao relative inability to clear all the material from the walls or to dispose of the large quantity of material $\stackrel{\oplus}{+}$ so taken in. These patients have a severe functional 7 impairment and most show a steady deterioration to chronic renal failure. In rapidly progressive $\stackrel{\mathbb{\Omega}}{\overparen{D}}$ glomerulonephritis the obvious lack of even $a \stackrel{\otimes}{\stackrel{\otimes}{2}}$ normal number of mesangial cells and of any evidence of significant removal of deposited material may account for the rapidity of the course of the ill- 
ness and the passage of plasma through the capillary basement membrane, with the subsequent formation of fibrin and stimulation of crescent formation. Most patients with this condition present with severe depression of renal function, in many amounting to acute renal failure, and there is usually a rapid deterioration of renal function.

In experimental animals mesangial cells are capable of removing material from the subendothelial region of the glomerular capillary wall (Farquhar and Palade, 1962; Kelley, 1970). In this respect they may be compared with fixed reticuloendothelial or otherwise phagocytic cells such as the Küpffer cells in the liver and the phagocytic cells of the lung. The mesangial cell is able to ingest colloidal material, eg, gold, iron, and carbon, proteins such as bovine serum albumin and ovalbumin (Mellors and Brzosko, 1961), and aggregated gammaglobulin (Michael et al, 1967). Proteins are rapidly taken up by the mesangial cells but may be detected only up to three days after ingestion. Complexes are also taken up, but unlike other proteins they persist for several weeks and produce structural glomerular changes (Mellors and Brzosko, 1961).

In human renal disease immune complexes and proteins such as complement and fibrin have been detected within glomerular capillary walls. It has been postulated that in many types of proliferative glomerulonephritis deposition of complexes with subsequent complement activation and fibrin deposition is the initial glomerular insult. This produces a reaction which includes mesangial and endothelial cell hyperplasia. There is thus an increase in glomerular cellularity, giving rise to both structural and functional disturbances.

The mesangial cell is probably important in maintaining the integrity, particularly the permeability, of the basement membrane. In experimental animals damage to the mesangial cells increases the permeability of the capillary wall (Kelley, 1970; Galbraith, 1971). The ability to remove deposited material from the glomerulus is therefore considered to be an important factor in promoting healing of the glomerular lesion.

Material deposited within the lumen or in the wall of the glomerular capillary can be removed by (1) lysis and absorption into the systemic circulation, (2) phagocytosis by circulating mononuclear cells, (3) passage through the capillary wall and excretion in the urine, and/or (4) phagocytosis by the glomerular reticuloendothelial (mesangial) cells.

1 Consequent upon the deposition of fibrin there is activation of plasminogen with the formation of plasmin. This produces lysis of the deposited fibrin to form fibrin/fibrinogen degradation products which enter the systemic circulation. In the pre- sence of glomerular damage these degradation products are excreted in the glomerular filtrate.

2 In certain forms of experimental glomerulonephritis there has been shown to be an infiltration of mononuclear cells following glomerular injury. These cells can actively phagocytose deposited material (Shigematsu and Kobayashi, 1971), but their importance in human glomerular disease is unknown.

3 Fibrin which is deposited within the glomerular capillaries is excreted in the urine as fibrin degradation products and there is good correlation between the amount of such products excreted and the deposition of fibrin within the glomerulus (Davison, Thomson, MacDonald, Rae, Uttley, and Clarkson, 1973).

4 In human glomerular disease it is probable that the most important route of removal of deposited material is by way of the mesangial cell. In the present study, most of the deposit in resolving or mild cases was detected within the mesangial regions, while in moderate disease most deposits were in the capillary wall. In progressive disease it is possible to speculate that the mesangial cells were unable to cope with the volume of material being deposited within the wall, thereby enlarging and obstructing capillaries. In addition it may be that the relative lack of material in mesangial regions in rapidly progressive disease was due to deficiency in numbers of mesangial cells or to an inherent or acquired defect in their phagocytic properties. In such cases a glomerular insult might result in the massive exudation of material into Bowman's space, with subsequent activation of the coagulation system leading to fibrin deposition and proliferation of the parietal epithelial cells. The phagocytic function of the mesangial cell would therefore seem to be of prime importance in restoring the glomerulus to normal, following deposition of abnormal material.

There are many factors which influence the uptake of material by the mesangial cell. The composition and quantity of antibody produced in response to an antigen (Pincus, Haberkern, and Christian, 1968), the ratio of antigen to antibody (Dixon, Feldman, and Vazquez, 1961), and the size, shape, and electrical charge of the complex formed (Cochrane and Hawkins, 1968) are all important factors in determining the rate of phagocytosis. In addition, certain drugs influence the rate of mesangial uptake (Germuth, Valdes, Senterfit, and Pollack, 1968) and may therefore be of great value in certain cases of glomerulonephritis.

The ultimate fate of immunoproteins or complexes once they have been taken up by the mesangial cells is unknown. Most probably in favourable cases they 
are metabolized by these cells, particularly by their lysosomes. However, the relationship of the mesangial cells to the cells of the juxtaglomerular apparatus makes it at least possible that any material which remains unassimilated by the cell is passed on to this structure. It may even be that such a process is responsible for the close association of active proliferative glomerulonephritis and hypertension. It is interesting to note that in mice, two hours after the intravenous injection of Imposil 200, there is histological evidence of iron within the mesangial regions and the juxtaglomerular apparatus (Kelley, 1970); Latta and Maunsbach (1962) demonstrated that after intravenous injection particles of Thorotrast could be demonstrated within the cells of the juxtaglomerular apparatus.

We are grateful for the technical assistance of Mr J. K. Rae, Miss Leslie Taylor, and Mr Robert Donaldson. Financial support has been given by the Lawson Tait Medical and Scientific Trust, the Scottish Home and Health Department, and the Scottish Hospital Endowments Research Trust. The immunofluorescence illustrations are the work of the Medical Illustration Service of the University of Edinburgh.

We are grateful to Dr A. Doig, consultant physician, Royal Infirmary, Edinburgh, for the clinical details of cases 14 and 19 , and to $\mathrm{Dr} \mathrm{J}$. L. Anderton, consultant physician, Western General Hospital, Edinburgh, for clinical details of cases 5 and 32.
References

Cochrane, C. G., and Hawkins, D. (1968). Studies on circulating immune complexes. III. Factors governing the ability of circulating complexes to localize in blood vessels. J. exp. Med., 127, 137-154.

Davison, A. M., Thomson, D., MacDonald, M. K., Rae J. K., Uttley, $\overline{\widehat{C}}$ W. S., and Clarkson, A. R. (1973). Identification of intrarenal $\overrightarrow{\overparen{D}}$ fibrin deposition. J. clin Path., 26, 102-112.

Dixon, F. J., Feldman, J. D., and Vazques, J. J. (1961). Experimental glomerulonephritis: the pathogenesis of a laboratory model ${ }^{\infty}$ resembling the spectrum of human glomerulonephritis. J.exp. $\overrightarrow{0}$ Med., 113,899-920.

Farquhar, M. G., and Palade, G. E. (1962). Functional evidence for $\overrightarrow{\vec{\omega}}$ the existence of a third cell type in the renal glomerulus: $\omega$ phagocytosis of filtration residues by a distinctive 'third' cell J. Cell Biol., 13, 55-87. Galbraith, S. L. (1971). The mesangium of the renal glomerulus. in
Scot. med.J., 16, 428-437.

Germuth, F. G., Jr., Valdes, A. J., Senterfit, L. B., and Pollack, A. D. $\omega$ (1968). A unique influence of cortisone on the transit of specific -1 macromolecules across vascular walls in immune complex disease. Johns Hopk. med. J., 122, 137-153.

Kelley, E. V. (1970). Microscopic investigations of glomerular lesions 을 produced by immunological mechanisms in experimentalanimals and human patients. MSc Thesis, University of Edin- $\bar{Z}$ burgh.

Latta, H., and Maunsbach, A. B. (1962). Relations of the centro-⿳亠丷厂 lobular region of the glomerulus to the juxtaglomerular apparatus. J. Ultrastruct. Res., 6, 562-578.

Mellors, R. C., and Brzosko, W. J. (1962). Studies in molecular pathology. I. Localization and pathogenic role of heterologous $\omega$ immune complexes. J. exp. Med., 115, 891-902.

Michael, A. F., Fish, A. J., and Good, R. A. (1967). GlomerularO localization and transport of aggregated proteins in mice. Lab Invest., 17, 14-29.

Pincus, T., Haberkern, R., and Christian, C. L. (1968). Experimentah్ chronic glomerulitis. J. exp. Med., 127, 819-832.

Shigematsu, H., and Kobayashi, Y. (1971). The development and fat of the immune deposits in the glomerulus during the secondary phase of rat Masugi nephritis. Virchows Arch. Abt. B. Zellpath? 8, 83-95. 